\title{
Dive, Dive, Dive: Accessing the Subsurface of Ocean Worlds
}

A Paper Submitted to the Planetary Science Decadal Survey

On Behalf of the Subsurface Needs for Ocean Worlds Working Group of OPAG

Submitted by:

SNOW Organizers

Britney Schmidt, OPAG, VERNE

Georgia Tech, britneys@eas.gatech.edu
Kate Craft, Europa STI

JHU APL, kate.craft@jhuapl.edu

\section{SESAME PIs \& Teams (Co-Authors)}

Thomas Cwik, JPL

Kris Zacny, Honeybee Robotics

Miles Smith,JPL

Vishaal Singh, Europa STI,

Arizona State University?

Bill Stone, Stone Aerospace
Georgia Tech VERNE:

Frances Bryson, Chase Chivers, Sara Pierson, Justin Lawrence, Taylor Plattner, Elizabeth Spiers, Andrew Mullen, Jacob Buffo, Nathan Daniel, Ashley Hanna, Glenn Mightsey, Natt Meister, Mohamed Nassif,

\section{Endorsers:}

Europa Signals Through the Ice:

Christine McCarthy, Lamont Doherty Earth Observatory; G. Wesley Patterson, Ralph D. Lorenz, JHU Applied Physics Laboratory; Christopher R. German, Michael V. Jakuba, Woods Hole Oceanographic Institution, Matthew Silvia, Woods Hole Oceanographic Institution; Alyssa R. Rhoden, Southwest Research Institute; Matthew E. Walker, U. Southern Maine

\section{Community Endorsers:}

Jeff Moore, NASA Ames; Linda Spilker,

JPL/Caltech; Marc Neveu, UMD/NASA

Goddard; Patricia Beauchamp, JPL/Caltech; Matthew Siegfried, CO Mines;

Sam Howell, JPL; Cynthia Phillips, JPL;
Morgan Cable, JPL; Christine McCarthy, LDEQ: Andrew Dombard, U Illinois, Chicago; Ganna Portayinka, LASP; Karyn Rogers, RPI; Shane Byrne, U Az; Evan Eschelman, Impossible Sensing; Robert Dziak, NOAA; Bryanna Henderson, JPL; Dale Winebrenner, $U$ Washington; Alison Murray, DRI; Brent Christner, U Florida; Carol Paty, U Oregon; Connor Nixon,

NASA Goddard; Michael Malaska, JPL; Erin Leonard, Jet Propulsion Laboratory,

Kalind Carpenter, JPL/Caltech; Krista

Soderlund, University of Texas at Austin; Zach Ulibarri, Center for Integrated Plasma Studies, University of Colorado; Heather Graham, Catholic University of America/NASA GSFC

\section{Flyby. Orbit. Land. Drill/Melt. Swim? Search for Life.}




\section{Dive, Dive, Dive: Accessing the Subsurface of Ocean Worlds}

We demonstrate Deep Access Ocean World missions can be ready for flight in ten years, with a balance of near-term missions and a 10-year technology development program to enhance achievements of the past decade. The goal of exploring and detecting life in oceans of the outer solar system is close to realization, should we choose to act.

Exploring the ocean worlds (OWs) of the outer solar system represents a growing interest in planetary science [1]. The importance of the search for life--a priority across the Planetary Science and Astrobiology communities (see OPAG, SBAG VeXAG, MEPAG, NfoLD, NOW white papers,)--elevates outer solar system satellites as compelling targets for flight programs throughout the coming decades. The potential of these bodies to inspire the public has driven support by congressional stakeholders, who have compelled NASA to establish an Ocean Worlds exploration program.

Vigorous program support and intense focus on the icy moons could, in the next 20 years, go as far as planning a subsurface expedition to an ocean world. ... If driven by astrobiology and science community participation, in a new interdisciplinary and interagency landscape that prizes innovation and achievement, such missions are possible within the next few decades. - 2017 NASEM Astrobiology Strategy (2017 NASEM [2])

We suggest prioritizing the following missions and technology development programs:

1) Extend the success of ICEE, ICEE-2, COLDTech and SESAME into a technology development program for $O W$ landed and subsurface missions, and keep PSTAR a growing annually-competed program. Such programs should fund the development of communications, access, sample handling and other critical systems.

2) Make strong investments in technology programs that achieve flight-ready life detection instrumentation, sampling \& sample handling, and optimized power systems such as RTGs, small RHUs, and better batteries.

3) Strongly couple science into technology programs and pre-phase $A$ activities to ensure that diverse perspectives are involved, enable participation across institutions, and maintain science relevance.

4) An OW lander (preferably to Europa) with a shallow drill should be selected for flight to achieve the science prioritized by the $O W$ community and provide feed-forward information to a future Deep Access $O W$ mission.

s) Complete SDT studies of a Europa Deep Access probe by 2030 to guide the development of a mission for the 2033-2042 decade, as well as an Enceladus lander with subsurface capability, such as a deep drill or a crevasse-deployed instrument.

Subsurface Missions to $O W$ s are Critical, Driven by High-Priority Science, and Achievable:

NASA's programs and missions should reflect a dedicated focus on research and exploration of subsurface habitability in light of recent advances demonstrating the breadth and diversity of life in Earth's subsurface, the history and nature of subsurface fluids on Mars, and potential habitats for life on ocean worlds. -NASEM 2017 pg. 3

Major advances in technology for OW exploration have occurred in the past ten years, both in service of NASA missions and derived from Earth exploration. Investments in OW instrumentation through the ICEE, ICEE-2 and COLDTech programs helped/are helping ready instruments for Europa Clipper and a Europa Lander mission. These investments (COLDTech in particular) have reduced technological risks of landed exploration in Europa's harsh environment, and feed forward to deep subsurface access missions. The 2018 Scientific Exploration Subsurface 
Access Mechanism for Europa (SESAME) program invested in end-to-end technology studies for subsurface access missions of $>15 \mathrm{~km}$, and leveraged the past decade of NASA ASTEP and PSTAR technology developments. The two-year SESAME program will produce, upon its 2021 completion, five studies distributed across institutions that evaluated access technology including drilling, communication, tether design, environmental conditions, and in some cases, the science enabled by such missions. Together these investments have helped refine mission design and codify advancements needed to realize subsurface missions. As a result, the challenges of Deep Access OW missions are now much more bounded, to a degree that, building from Cassini and the Europa Clipper mission, these missions could be developed to fly in the decade following this one.

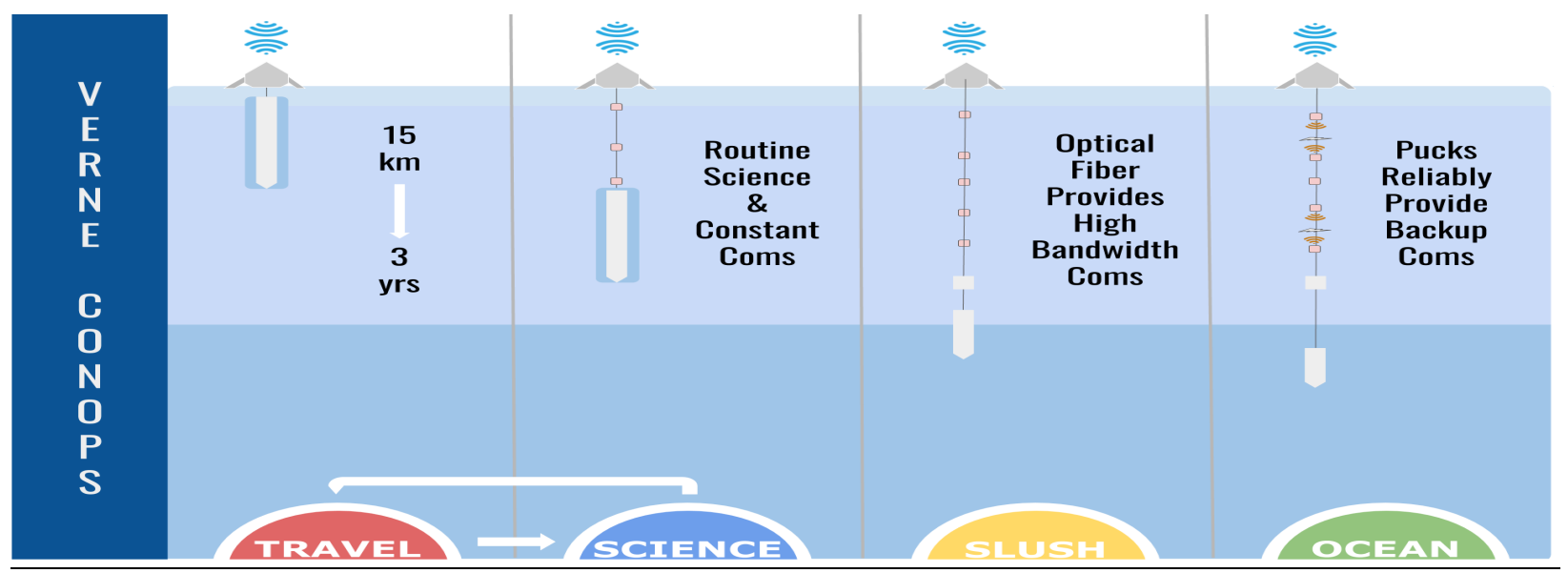

Figure 1: Example Operations for a Deep Access mission (VERNE Conops). Thermal or mechanical drilling progresses through the ice shell, delivering the probe to the ocean. In this concept, sampling liquids every $1 \mathrm{~km}$ and ocean profiles are baseline.

\section{Technologies ready for missions in the next decade}

Access \& Sampling Technologies: Prior to Deep Access missions, a surface landing should be selected for an OW this decade. Shallow drilling ( 1-5 m), while not required in order to send a Deep Access mission, would advance future access operations by informing on material properties of the surface. Shallow drills used to explore terrestrial planets (e.g. Phoenix \& InSight) could be used in the outer solar system. Thanks to missions like VIPER, 1-m class shallow drills applicable to OWs are nearly flight ready. Compared with other sampling methods, drills offer more feedforward information to Deep Access missions since they interact with the surface in a similar way, while also achieving deeper, less altered collections of samples than from the radiation and impact processed near-surface. Deeper sampling drills (10 m class) intended for the Moon and Mars are expected to fly in the 2020's and their technology may be useful in furthering efforts for OWs [3].

\section{Technologies in development with potential to reach TRL 6 or better by 2030}

Access Technologies: A host of access technologies are expected to reach TRL 4-5 by the end of 2022 (Table 1). These include Philberth-probes and their descendants (IceDiver) [4] [5], hot water jet drilling demonstrated on VALKYRIE [6], mechanical and hybrid thermo-mechanical drills such as SLUSH [7] and envisioned for VERNE [8]. Given current progress, field tests of integrated systems are planned in the very near term, and end-to-end systems would be possible by 2030 . Continuing the SESAME program or similar competed technology development programs would ensure readiness for the next decade and engage the widest possible swath of the community. 
Table 1. Summary of Technologies Envisioned for Subsurface OW Missions. $\boldsymbol{V}$ indicates system level partial completion or (relevant components), and $\nabla$ indicates the phase has been/will be completed by end of 2022. TRL is estimated for ocean worlds by end of 2022 .

\begin{tabular}{|c|c|c|c|c|c|c|}
\hline Technology & Version & TRL & Progress (Notes) & Bench & Field & Flight \\
\hline \multirow[t]{2}{*}{ Fiber } & Fiber Optic & $4-5$ & $\begin{array}{l}\text { Mechanical \& strength tests, } \\
\text { breaking/shock tests; Europa } \\
\text { STI }\end{array}$ & $\nabla[9]$ & $\nabla[9]$ & $(\sqrt{ })$ \\
\hline & Copper & $4-6$ & Needs testing; Too heavy? & $\checkmark$ & $\nabla[10]$ & $(\sqrt{ })$ \\
\hline \multirow[t]{7}{*}{ Drilling } & Shallow coring & 6 & $\begin{array}{l}\text { Not flown to OWs; Need sample } \\
\text { handling systems }\end{array}$ & $\nabla$ & $\begin{array}{l}\nabla[11] \\
{[7][12]}\end{array}$ & $\nabla[13]$ \\
\hline & Deep-Thermal & & $\begin{array}{l}\text { Philberth probes since } 60 \text { 's, } \\
\text { limited to small probes }\end{array}$ & $\nabla$ & $\nabla[4]$ & \\
\hline & & $4-5$ & $\begin{array}{l}\text { Ice Mole; navigated into Taylor } \\
\text { glacier }\end{array}$ & $\nabla$ & $\nabla[14]$ & \\
\hline & $\begin{array}{l}\text { Deep-Hot water } \\
\text { jetting }\end{array}$ & $4-5$ & $\begin{array}{l}\text { E.g. VALKYRIE to } \sim 300 \mathrm{~m} \text {; } \\
\text { another method is needed to } \\
\text { start drilling }\end{array}$ & $\nabla$ & $\begin{array}{l}\nabla[6] \\
{[15]}\end{array}$ & \\
\hline & $\begin{array}{l}\text { Deep-Thermo- } \\
\text { Mechanical }\end{array}$ & $4-5$ & E.g. Honeybee SLUSH & $\nabla$ & $\sqrt{ }[7]$ & \\
\hline & $\begin{array}{l}\text { Deep- Mecha- } \\
\text { nical/Rock }\end{array}$ & 6 & $\begin{array}{l}2022 \text { Drill concepts headed for } \\
\text { Lunar application }\end{array}$ & $\nabla$ & $\nabla[7]$ & $\checkmark[3]$ \\
\hline & $\begin{array}{l}\text { Deep- } \\
\text { Mechanical/Ice }\end{array}$ & 5 & $\begin{array}{l}\text { E.g. Autogopher-2, Planetary } \\
\text { Deep Drill }\end{array}$ & $\nabla$ & $\begin{array}{l}\checkmark[16] \\
{[11][17]}\end{array}$ & \\
\hline \multirow[t]{5}{*}{$\begin{array}{l}\text { Communi- } \\
\text { cation }\end{array}$} & $\begin{array}{l}\text { RF Antenna - in } \\
\text { ice }\end{array}$ & $4-5$ & $\begin{array}{l}632 \mathrm{~m} \text { link for over } 1 \mathrm{yr}(50 \varnothing \mathrm{x} \\
300 \mathrm{~mm} \text { device), } 2500 \mathrm{~m} \text { link } \\
\text { (HB9CV antenna) }\end{array}$ & $\nabla$ & $\begin{array}{l}\nabla[18] \\
{[19]}\end{array}$ & $(\sqrt{ })$ \\
\hline & Acoustics & 5 & $\begin{array}{l}\text { Piezoelectric transducer } \\
\text { operating at cryogenic } \\
\text { temperatures on Titan } \\
\text { (Huygens) }\end{array}$ & $\nabla$ & $\nabla$ & $\nabla[20]$ \\
\hline & \multirow[t]{2}{*}{ Acoustics in-ice } & 5 & $\begin{array}{l}\text { IceCube } \& \text { SPATS operational } \\
\text { since } 2007 \text {, acoustic array (10- } \\
100 \mathrm{kHz} \text { ) beneath south polar ice }\end{array}$ & $\begin{array}{l}\nabla[21] \\
{[22]}\end{array}$ & $\begin{array}{l}\nabla[21] \\
{[22][23]}\end{array}$ & $(\sqrt{ })$ \\
\hline & & $3-4$ & VERNE Acoustic System & $\checkmark[24]$ & & \\
\hline & $\begin{array}{l}\text { Acoustic- in } \\
\text { water }\end{array}$ & 5 & $10-100 \mathrm{~km}$ comm. links & $\nabla[25]$ & $\begin{array}{l}\square[26] \\
{[27]}\end{array}$ & \\
\hline
\end{tabular}


Deep Access Technologies for ocean access vary in their method of travel. A recent concept study [28] explored a pair of $\sim 5 \mathrm{~m}$ long probes that would use nuclear power to melt through 20 $\mathrm{km}$ of Europa's ice in 3 years, finding feasibility using nuclear sources both existing (GPHS bricks) and in advanced development (the NASA/DOE Kilopower advanced reactor). Mechanical drilling (either rotary or rotary-percussive) has demonstrated the fastest descent rates, as opposed to pure melting and a combination of mechanical and thermal drilling [3]; Icebreaker has been tested in Antarctica and reached $3 \mathrm{~m}$ [11]. The Planetary Deep Drill uses an anchor to lock the wireline drill in the borehole to provide anti-torque, and allows the drill to "inchworm" down the borehole, reaching depths $>10 \mathrm{~m}$ in gypsum [17]. WATSON wireline drill penetrated to $111 \mathrm{~m}$ in Greenland ice. SLUSH uses both thermal melting and mechanical drilling (rotary and rotary-percussive); results show that slushing is more energy efficient than either melting or mechanical drilling alone, it is faster than melting but slower than pure mechanical drilling. Descent rate and energy usage can be optimized through cycling [7] .

Field tested prototypes of many technologies already exist, but require further tests and migration of field-optimized versions to flight systems. The challenges that all of these systems face are their size, proven penetration depths, and thermal management systems. In particular, limitations of the RTG systems currently available make the access technologies more massive and wider than is ideal, reducing efficiency. For autonomous access technologies at Europa, navigation/hazard avoidance is also a challenge - fins, waterjets, reversible spooling tethers and differential heating all aid in steering and hazard avoidance and have been used on ice drilling platforms in the lab and field, but advanced radar/acoustic systems for navigation and hazard identification are necessary technology to develop.

Sample Handling: Sample handling is a key driver for life detection technologies that would be incorporated into future subsurface missions (see NfoLD 2020 white paper). Currently, there are no flight-ready sample handling systems that manipulate liquid samples; however, these are in development and have a strong heritage in Earth's oceans at pressures that subsurface OW missions would encounter. As currently designed, the Europa Lander will collect cryogenic ice at the surface as a powder or chips of ice smaller than $3 \mathrm{~mm}$ using a saw blade and scoop, and distribute samples to instruments through a pneumatic system [29]. This system is a step forward toward OW sampling and is undergoing development. Relative to a new system, it is comparatively low technical risk, however, this method is destructive to the sample and is thus potentially confounding to some analyses.

Drilling technologies that do not require large overhead forces (referred to as the weight on bit) will enable the search for in situ biosignatures in planetary subsurfaces. These technologies will need to be able to collect samples without altering their composition significantly (e.g., Kereszturi 2016). -2017 NASEM pg. 96 [2]

Technology developments to go beyond powders, to solid samples and liquid sampling systems, should be prioritized in the next ten years. A positive step would be handling ice cores, potentially through melting or sectioning, as is standard on Earth for physical, chemical, and biological analysis of ices [30]. Some early technology investments have made progress on liquid sampling [31], [32]) that could be accelerated for a later decade launch. Applicable sampling and sample handling systems on Earth typically collect multiple samples of water for analysis on land, or analyze the water in situ [33], which would translate to flow-through instruments in sample handling systems as, for example, proposed by the VERNE SESAME study [34]. Systems such as the McLane Remote Access Sampler (RAS) [35], AquaLAB [36], and MBARI 3G-ESP G [33] are already rated at Europa-relevant pressures. Some systems are used aboard underwater mobile 
vehicles (Gulper, AquaLAB, 3G-ESP, RAS). The RAS has been deployed for up to 3 years in icy environments, enabling sampling and profiling, indicating a persistent system traceable to OW missions. A water sampling and routing system that feeds a holographic microscope onboard Icefin will be tested in Antarctica in 2021 [37]. The VERNE SESAME study will advance a capable, science enabling liquid sample handling system to TRL 3 or 4 by 2022, and demonstrate parts of the subsystem in 2021 and 2022 on underwater vehicles [34]. TRL 6 is achievable by mid 2020s.

Communications: For a deep-access mission to Europa, SESAME estimates at least 3 years of drilling, during which a tether failure would end the mission; this makes a secondary, wireless communications link a necessary supporting technology to ensure mission success.

Tether systems: Among the largest concerns in preparing for a through-ice mission is the durability of tethers that enable both power and high data rate in a variety of unknown conditions on an OW. While currently not TRL 6, funded SESAME activities of the Europa STI team [38] are characterizing the robustness of tethers to determine (a) the maximum shear stress (and displacement) they can sustain in ice faults on Europa, prior to failure, informing us on viable/unviable regimes for deployment, (b) their optical performance for communications, and (c) how they fail (determined by microscopic analyses). These strength-enhanced fiber optic systems are already in use for through and under ice exploration by vehicles like [39]. In initial tests at $260 \mathrm{~K}$, the fibers showed resistance to shear, stretching and sliding along the ice-fault interface, and deformed the ice around them; optical capabilities were fully recovered post testing. By 2022, this work will extend the experimental conditions to include lower temperatures, fatigue, and long duration tests, along with identifying effects of pre-tension on tensile strength \& communication performance. Fiber optic tethers are also science instruments capable of measuring the thermal profile of the ice shell and the location of fractures [38], mimicking their use as geophysical tools in the evaluation of ice sheet dynamics on Earth [40] [41]. Development over the coming decade would allow these TRL 2-4 systems to achieve TRL 6.

Radio frequency $(R F)$ currently exists that enables reliable, through-ice communication in terrestrial analog environments (similar to the Europan cryogenic ice regime), Table 1. RF communication through glaciers on Earth has been demonstrated over years and through 100's of meters [18]. Studies by the SESAME Europa STI team are examining effects of frequency and antenna types and improve antenna efficiency for small pucks. Challenges for RF communication also lie in decreased transmission through ice-water-salt mixtures.

Acoustic technologies could be sufficiently robust to close data link through even mixed or liquid regimes [21] [22] [42] [43] [44] [45]. Low-frequency $(<40 \mathrm{kHz})$ acoustic signaling has been used underwater since the 1980 's, and can now reliably communicate over $10 \mathrm{~s}$ to $100 \mathrm{~s}$ of kilometers [25] [26] [46] [47] [27]. More notably, piezoelectric transducer technology was successfully utilized $(10 \mathrm{kHz}$ signal) in cryogenic temperatures by the Huygens probe on the surface of Titan. SESAME activities suggest piezoelectric materials can be adapted to accommodate communication through ice, but expanded benchtop testing and field qualification are necessary.

Guidance, navigation, and control: GNC for an access mission allows advanced operations such as vehicle control and identification of hazards and science targets. Three key enablers of this technology are: 1) understanding properties of Europa's ice shell; 2) a compact system for detection and classification of in-ice objects; and 3) melt probe maneuverability. Investigation of ice properties by the scientific community should be coupled with future technology programs, and will be advanced by future missions, namely Europa Clipper and the proposed Europa Lander. Detection of hazards is project specific, but progress has been made in terrestrial systems [e.g. 
VALKYRIE, ICEMOLE]. These technologies require increased range and more relevant environmental testing. Navigation in ice has been proposed through a range of methods. IceMole achieved an in-ice turn radius of $10 \mathrm{~m}$ using differential melting; VALKYRIE achieved a turn radius of roughly $80 \mathrm{~m}$ using differential water jetting. Autonomous trajectory control using an onboard power has yet to be demonstrated.

Power systems: Further development is needed in power and thermal systems. RTG systems currently available were not designed for the compact form factors of Deep Access probes or the needs of small subsystems such as communications pucks. SESAME efforts and the COMPASS study [28] all show that the mass and diameter of the RTG system is the primary driver of the diameter and mass of Deep Access probes. Current development of smaller, finless designs and dense RTG pucks would reduce mass and diameter of the melt probes. The major development needed for communication relay systems is advanced, small power, such as small form factor Radioisotope Heater Units (RHUs) or better long-life, cold-adapted batteries. Other advanced power systems are likely too early in development to be flight qualified for the next decade, while RTG systems are sufficient to meet the needs of Deep Access missions. Strong investments in the next generation of RTGs benefits all planetary communities, planetary targets, and in particular the outer solar system where solar power is ineffective.

Recommendations for the next Decade:

Technology Roadmap: Many key technologies for Deep Access Probes are in development prior to the start of the 2023-2033 decade, and targeted investments should continue to be made to advance them and retire risk. Similar to the Deep Access developments outlined here, programmatic considerations that affect "new" technologies, particularly life detection science payloads, can be found in the NfoLD 2020 white paper. The success of ICEE, ICEE-2, COLDTech PSTAR and SESAME thus far suggests that by continuing such programs, technology maturation could be achieved that also distributes NASA's investments across institutions through competed opportunities that would engage a diverse cross section of thinkers in the development of these missions, including in the Earth oceans and polar communities. We recommend:

1) Extending the success of ICEE, ICEE-2, COLDTech and SESAME into a technology development program for $\mathrm{OW}$ landing and subsurface missions, and keeping PSTAR a growing annually competed program. Such programs should fund the development of communications, access, sample handling and other critical systems.

2) Making strong investments in dedicated technology programs that achieve flight- ready life detection instrumentation, sampling \& sample handling, and optimized power systems such as RTGs, small RHUs, and better batteries.

3) Strongly coupling science into technology programs and pre-phase A activities to ensure that diverse perspectives are involved, enable participation across institutions, and maintain science relevance. Planetary missions are interdisciplinary in nature and should include funded scientists and collaborations with instrument teams to keep projects relevant to the science that drives them, and instruments likely to be selected.

Missions for the near term: Baseline science instrumentation already exists and is flight-ready for an OW lander, such as envisioned by the 2012 \& 2017 Europa Lander SDT reports. An added sampling drill would feed-forward directly to a later deep access probe. A return to Enceladus in the next decade informs the most appropriate course of action for Enceladus, i.e. whether plume sampling is sufficient or deep access is needed. We recommend: 
4) An OW Lander (preferably to Europa) with a shallow drill be selected for flight to achieve the science prioritized by the $\mathrm{OW}$ community and provide feed-forward information to a future Deep Access OW mission.

Missions for the future: The key message is this: we need to reach the ocean of an OW [1] [48] [49] (See supporting white paper submissions by Phillips et al 2020, NfoLD 2020, NOW 2020). Here, we have demonstrated that this is tenable within the next two decades with the technology underway given a robust funding program in the coming decade. We recommend:

5) Completing SDT studies of a Europa Deep Access probe by 2030 to guide the development of a mission for the 2033-2042 decade, as well as an Enceladus lander with subsurface capability, such as a deep drill or a crevasse-deployed instrument.

References:[1] Hendrix, A. R. et al., (2019), Astrobiology, 19(1), 1-27. [2] NASEM (2019). Washington, DC: The National Academies Press, 1-188. [3] Zacny, K. et al (2020). In Advances in Terrestrial and Extraterrestrial Drilling: Ground, Ice, and Underwater. Forthcoming, CRC Press/Taylor \& Francis Group LLC. [4] Philberth, K., (1976), Lincoln, NE , 117-131 [5] Winebrenner, D.P. et al, (2013), Journal of Geophysical Research(112), 1-2 1-2. [6] Stone, W. et al., (2018), Springer, 47-165.[7] Zacny, K. et al., (2018), IEEE Aerospace Conference, 1-14. [7] Zacny, K. et al., (2018), IEEE Aerospace Conference, 1-14. [8] Meister, M., et al., (2019), AbSciCon, Seattle, WA. [9] Glaesemann, G.S., (2017), 36-54. [10] Stone, W., et al., (2018), in Outer Solar System, 47-165. [11] Zacny, K., et al., (2013), IEEE Aerospace Con, 1-11. [12] Zacny, K., et al, (2014), 2014 IEEE Aerospace Conference, 1-12. [13] Sproewitz, T., et al., (2019), 2019 IEEE Aerospace Con, 1-14. [14] Niedermeier, H. et al., (2014), 2014 IEEE/ION Pos, Loc. \& Nav.Symp., 959-975. [15] "Hot water drilling in Antarctic ice", World Pumps, 2012:6, 32-35. [16] Ciszewski, M. et al., (2015), 10th RoMoCo, 84-90. [17] Paulsen, G. et al., (2016), 47th LPSC, 1-2. [18] Smeets, C. J. P. P., et al., (2012), J. Glac., 58(211), 841-48. [19] Martinez, K., et al., (2005),

REALWSN'05, 1-5. [20] Zarnecki, J C., et al. 2005. Nature 438, no. 7069 : 792-795. [21] Price, P. B., (2006), JGR, 111(B2), 1-9. [22] Price, P. B., (1993), Nuclear Inst. \& Methods in Phys, Res. A, 325(1-2), 346-56. [23] Lishman, B., (2013), Annals Glac., 54(64), 124-34. [24] Pierson, S. et al, (2020). AGU 2020. [25] Hansen, Joseph T. "Link Budget Analysis for Undersea Acoustic Signaling," n.d., 60. [26] Stojanovic, Milica. "On the Relationship Between Capacity and Distance in an Underwater Acoustic Communication Channel," n.d., 7. [27] Growth of Underwater communications Technology in the Navy. [28] Oleson, S. et al. (2019) Compass Final Report: Europa. [29] Dooley, J., (2018),IEEE Aerospace Con., 1-10. [30] Thomas, D. N., et al., (2003), Sea Ice: An Introduction to its Physics, Chemistry, Biology and Geology, 267-302. [31] Southard, A. E. etal., (2016), 47th LPSC, 1-2. [32] Reh, K. et al., (2016), IEEE Aerospace Conference, 1-8. [33] Scholin, C. A. et al., (2017), Oceanography, 30(4), 100-113. [34] Bryson, F.E. et al, (2020), 2020 AGU, online. [35] "Remote Access Sampler User Manual", Mclanelabs.com, 2018. [36] Dodd, P. A. et al., (2006), J. Atmos. Oceanic Technol., 23(12), 1759-1767. [37] Mullen, A.D et al (2020) OCEANS 2020 MTS/IEEE, Online. [38] Singh, V., et al., (2019), AGU Fall Meeting. [39] Meister, M. et al., (2018), OCEANS 2018 MTS/IEEE Charleston, 1-5. [40] Zumberg, (2002). J. Glac., 217225. [41] Stern et al 2013, JGR Oceans 117, 7036-7048. [42] Vogt, C. et al., (2008) The Journal of the Acoustical Society of America 124, no. 6, 3613-18. [43] Manthei, G. et al., (2006), J. Acoustic Emission (24), 179-186. [44] Gow, A. J., (1971), JGR 76 no. 11, 2533-41. [45] Kuroiwa, D., (1964), "Internal Friction of Ice. III ; The Internal Friction of Natural Glacier Ice," n.d., 15. [46] Eswara, E. et al., (2011), IEEE Tech. Students' Symp., 65-70. [47] Chaitanya, D.E. et al, (2011), IEEE Tech. Student Symp., 65-70. [48] Schmidt, B. E. (2020). in Planetary Astrobiology, UAz Press. [49] Soderlund et al, (2020). Space Sci Rev, 216:80. 